\title{
Design and Fabrication of Segway
}

\author{
Yash P. Bagade ${ }^{1}$, Vijay S. Dhotre ${ }^{2}$, Sumit P. Nanaware ${ }^{3}$, Hemant M. Pawar ${ }^{4}$ \\ Department of Mechanical Engineering, Vidya Pratishthan's Kamalnayan Bajaj Institute of Engineering and \\ Technology, Maharashtra, India. ${ }^{1,2,3,4}$
}

\begin{abstract}
Designing and development of Segway Human Transporter covers the modelling and design of co-axial, two wheeled transport vehicle. The paper addresses how the previous disadvantages of segway design were overcame without comprising the features of the original segway. The vehicle comprises of two wheels on either side of the frame. The vehicle is designed to produce zero pollution and is fabricated with cost reduction and complete user safety in mind. It also includes additional features that greatly enhance the overall user friendliness of the vehicle. Furthermore, paper focuses on calculations and necessary design parameters required to fabricate even the simplest type of segway.The paper also discusses how with minimum mechanical components, minimum electronic components a maintenance free segway can be designed and how operator with minimal practice can ride it with great ease.
\end{abstract}

Keywords: Green vehicle, Personal transporter, Self balancing, Fail safe, Zero pollution.

\section{INTRODUCTION}

The Segway PT is a two-wheeled, self-balancing, battery-powered electric vehicle invented by Dean Kamen. It is produced by Segway Inc. of New Hampshire. The segway PT consists of gyroscopic sensors and accelerometers. The rider commands the PT to go forward or backward by shifting their weight forward or backward on the platform. In the process, the rider establishes and then maintains a desired speed by modulating the extent and duration of their fore/aft weight shifts. To turn and steer, the rider shifts the handlebar to the left or right. The PT responds by adjusting the speeds of the wheels in opposite directions causing the PT to yaw and, if not traveling forward or backward, turn in place. At speed, the amount of shift of the handlebar corresponds to the amount of left or right lean required by the rider to balance themselves on the platform during a turn. The balancing technology for the operation of the Segway was invented by Dean Kamen to mimic the way the human body balances itself. Its balancing mechanism operates like how the fluid in the inner human ear sends signals to the brain when the body shifts. This Technology is known as dynamic stabilization. Dean Kamen, the machine's inventor, held especially high hopes for the Segway. In an interview with Time Magazine, he claimed that his machine "will be to the car what the car was to the horse and buggy.".

However segway hasn't really lived upto its hype. The major hurdle in limited use of segway is it's too costly and hence people and organisation with upper financial status are only able to afford it. This naturally defeats the purpose of making segway a affordable daily personal transportation vehicle. The cost of segway in India is around 3 lakhs excluding taxes. This original segway is quite high priced for a college campus or even for a medium scale industry for that matter. Another major hurdle with commercially available segway is its safety. It is speculated that owner of segway Inc. himself died in tragic accident due to failure of gyroscopic unit of his segway ${ }^{1}$.This implies the question of operator safety is of grave importance while designing such a vehicle.

From above mentioned concerns, it is clear that buying individual vehicles and giving them out for rent or for personal use is not feasible. Hence, the idea of a vehicle that is easily affordable, is equally safe and yet eco friendly was putforth.Here,we tried to address all the disadvantages of the segway as discussed above. The development of suitable goals and specifications were crucial to the project's success as they guided both the design and aims of our team. Hence, another aim of the paper can also stated as "development of specification of the original segway Human transporter."

\section{PROBLEM STATEMENT}

- Segway is expensive and its market price is quite high. Hence, majority of the masses are not able to afford it. Cost of the product has always been the deciding factor of a product's success. Because of its high price the segway has failed to gain more customers even though the product is revolutionary.

- If the gyroscopic unit of the segway fails, the chances of fatal accidents of operator are tremendous. The gyroscope works with tilt of the handle bar as input. If handlebar is titled beyond a certain angle the unit will fails and operator may fell off.

- The structure of the segway is complex. This means that maintenance will be more. This adds to the operating cost of the vehicle. 
UGC Approved Journal

\section{DESIGN PARAMETERS}

Following are the design considerations for designing the segway :

- Coefficient of Friction of marble $=0.012$

- Coefficient of Friction of asphalt $=0.7$

- Maximum gradabiity $=5^{0}$

- Maximum Rotation speed=1 RPS

- Gear Reduction ratio=1:50

\subsection{Design Calculations ${ }^{2}$}

TTE=Total Tractive Effort

$\mathrm{RR}=$ Rolling Resistance

$\mathrm{GR}=$ Grade Resistance

$\mathrm{FA}=$ Acceleration force

$\mathrm{GVW}=$ Gross vehicle weight (with operator)

$\mathrm{R}_{\mathrm{w}}=$ Radius of Wheel

$\mathrm{R} 1=$ Reaction Coefficient

MTT=Maximum Tractive torque

Step1: Determine Rolling Resistance

RR $=$ GVW x Surface Friction

$=40 \times 9.81 \times 0.012$

$=4.7088 \mathrm{~N}$

Step 2:- Determine Grade Resistance (GR)

GR $=$ GVW $x \sin \alpha$

$=40 \times 9.81 \times \sin 5$

$=34.1999 \mathrm{~N}$

Step 3:- Determine Acceleration Force (FA)

$\mathrm{FA}=(40 \times 9.81 \times 1) / 9.81134 \mathrm{x} 2$

$=5.2 \mathrm{~N}$

Step 4:- Total Tractive Effort

$\mathrm{TTE}=\mathrm{RR}+\mathrm{GR}+\mathrm{FA}$

$=4.7088+34.1999+5.2$

$=44.1087 \mathrm{~N}$

Step 5:- Determine Wheel Motor Torque

$\mathrm{Tw}=\mathrm{TTE} \times \mathrm{Rw} \times \mathrm{R} 1$

$=44.1087 \times 0.17 \times 1.15$

$=8.6232 \mathrm{Nm}$

Step 6:- Calculating maximum torque

$\mathrm{MTT}=\mathrm{Ww} \times \mu \mathrm{xw}$

$$
=40 \times 9.81 \times 0.2 \times 0.17
$$

$=13.3416 \mathrm{Nm}$

Step 7:- Required Power

$\mathrm{P}=(2 \mathrm{x} \pi \mathrm{xNxMTT}) / 60$

$=(2 \times \pi \times 60 \times 13.3416) / 60$

$=41.91$ watt

Power Supplied By Selected Battery $=$ V x I

$$
\begin{aligned}
& =12 \times 7.2 \\
& =86.4 \mathrm{~W}
\end{aligned}
$$

Since Power supplied > Power required, the battery selection is correct and will fulfill our requirement.

Force $=130 \times 9.81=1275.3 \mathrm{~N}$

Step 8: Shaft Design:

Total Force acting on chassis $=1275.3 \mathrm{~N}$

As, total force acting on chassis is equally distributed on two wheels

$\mathrm{RA}=\mathrm{RB}=1275.3 / 2=637.65 \mathrm{~N}$ 
UGC Approved Journal

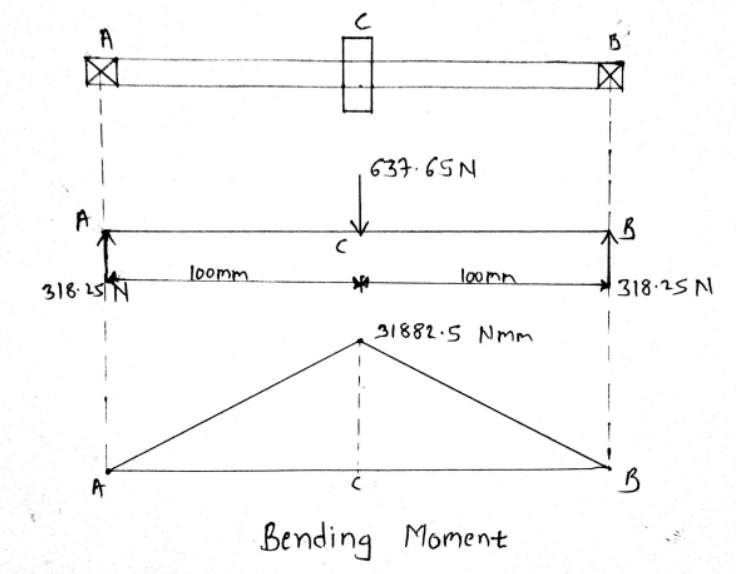

Fig.1 Forces on shaft

For shaft we are selecting C45 material.

So, for C45 material

Syt $=$ Yield strength of shaft material ${ }^{8}=320 \mathrm{~N} / \mathrm{mm} 2$,

Sut $=$ tensile strength of shaft material ${ }^{8}=580 \mathrm{~N} / \mathrm{mm} 2$,

According to A.S.M.E. code,

$\tau_{\max }=0.75 \mathrm{x}(0.18 \mathrm{x}$ Sut $)$

$=0.75 \times 0.18 \times 580$

$=78.3 \mathrm{~N} / \mathrm{mm} 2$

OR

$=0.75 \times(0.3 \mathrm{Syt})$

$=0.75 \times 0.3 \times 320$

$=72 \mathrm{~N} / \mathrm{mm} 2$

$\tau_{\max }=72 \mathrm{~N} / \mathrm{mm} 2$ (Selecting minimum value),

Now, Torque on shaft

$\mathrm{P}=(2 \pi \times N \times T) / 60$

$40=(2 \pi \times 60 \times \mathrm{TT}) / 60$

$\mathrm{T}=12.73 \times 103 \mathrm{~N}-\mathrm{mm}$

Bending moment on shaft.

$\mathrm{RA}=\mathrm{RB}=637.65 / 2=318.825 \mathrm{~N}$

Where,

$\mathrm{RA}=\mathrm{RB}$ are the reactions acting on shaft

Max. BM at $\mathrm{P}$,

$\mathrm{M}=\mathrm{RA} \times 100=31882.5 \mathrm{~N}-\mathrm{mm}$

Diameter of shaft based on strength

Equivalent torque,

$\left.\mathrm{Te}=\sqrt{ }(\mathrm{KbxM})^{2}+(\mathrm{KtxT})^{2}\right)$

Where,

$\mathrm{Kb}=$ combine shock and fatigue factor applied to bending moment

$\mathrm{Kt}=$ combine shock and fatigue factor applied to torsional moment

$\mathrm{Te}=\sqrt{ }(1: 5 \times 31882: 5)^{2}+(1 \times 12730)^{2}$

$\mathrm{Te}=49489.02 \mathrm{~N}-\mathrm{mm}$

$\tau_{\max }=(16 \times \mathrm{Te}) /\left(\pi \mathrm{d}^{3}\right)$

$72=(16 \times 49489.028) /\left(\pi \mathrm{xd}^{3}\right)$

$\mathrm{d}=15.18 \mathrm{~mm}$

So, for safety we are selecting the shaft

Diameter $\mathrm{d}=20 \mathrm{~mm}$.

Step 9: Selection of bearing

As load acting on bearing consist of two components Radial and Thrust. So we have used single row deep groove bearing. This bearing has high load carrying capacity and suitable for high running speed.

Where,

$\mathrm{d}=$ Inner diameter of bearing in $\mathrm{mm}$ 
UGC Approved Journal

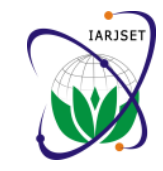

International Advanced Research Journal in Science, Engineering and Technology ISO 3297:2007 Certified

Vol. 4, Issue 6, June 2017

$\mathrm{D}=$ Outer diameter of bearing in $\mathrm{mm}$

$\mathrm{B}=$ Axial width of bearing in $\mathrm{mm}$

$\mathrm{C}=$ Dynamic load capacity in $\mathrm{N}$

$\mathrm{Co}=$ Static load capacity in $\mathrm{N}$

Now,

$\mathrm{P} 0=\mathrm{X} 0$ Where,

$\mathrm{P} 0=$ equivalent static load, $\mathrm{N}$

For $=$ Static radial load,

For Single row deep groove ball bearing,

$\mathrm{X} 0=$ Static radial factor $=0.6$

Substituting the values we get,

$\mathrm{P} 0=1275.3 \mathrm{~N}$

As, $\mathrm{C} 0>\mathrm{P} 0$

Design is safe.

Bearing selected is 6004 .

\section{SETUP}

\subsection{Frame}

Frame is the most important part of Segway. It is rectangular in shape and has dimensions as $710 \times 515 \times 2 \mathrm{~mm}$. In this part four vertical sectional bar jointed in between two horizontal section of iron angles. The whole jointed section again sliced into three another vertical sections for the purpose of compactness as shown in figure. Those three sections of frame are jointed each other by using butt type door lock hinged. The type of iron angle is L-shape iron angle. Due to the use of hinges we can fold the Segway and keep it in small space wherever is required. One solid plate is kept on the frame for ease of standing and other component spacing purpose like battery, water bottle, bag with any material etc. The solid plate with the thickness of $2 \mathrm{~mm}$ is also cut into three sections and jointed by welding. The locking arrangement is used for the ease of driving, because due to the slices of frame into three parts it may fluctuate while driving which causes accident. The rectangular plates are mounted at the both side of the frame in vertically downward direction. This plate consists of a bearing mounted in it and fixed by welding the outer section of bearing and inner section of plate.

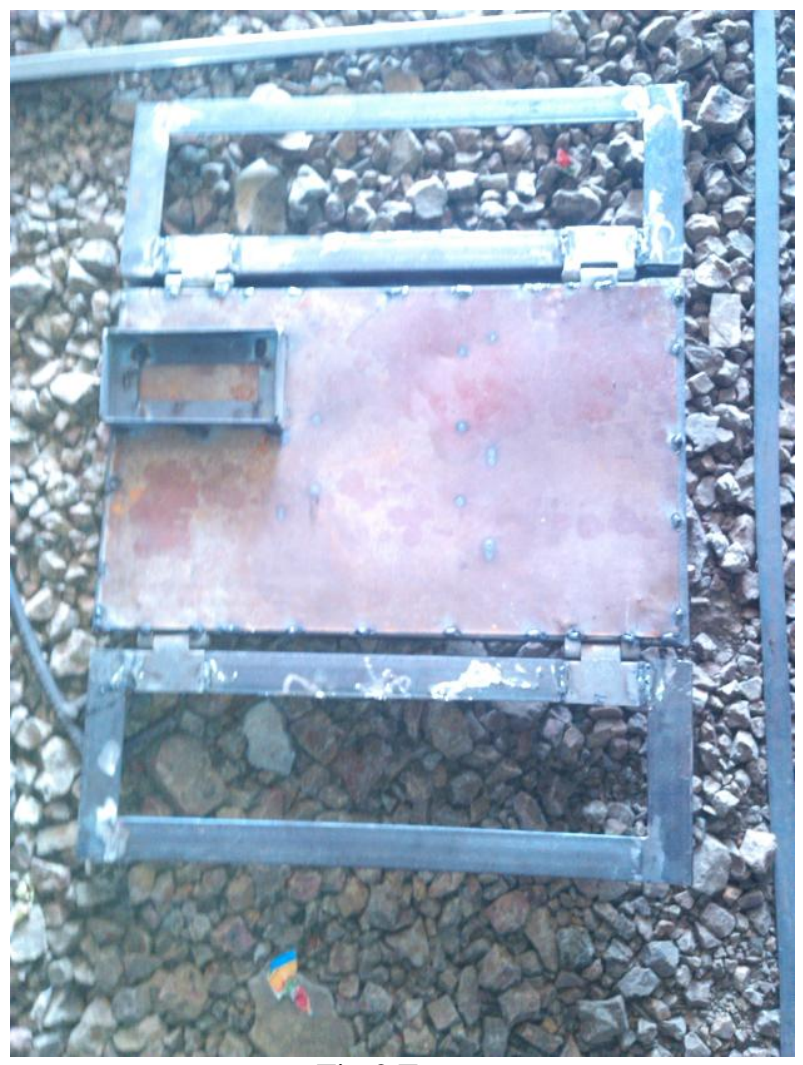

Fig.2 Frame 


\section{UGC Approved Journal}

\subsection{Bearing mounting}

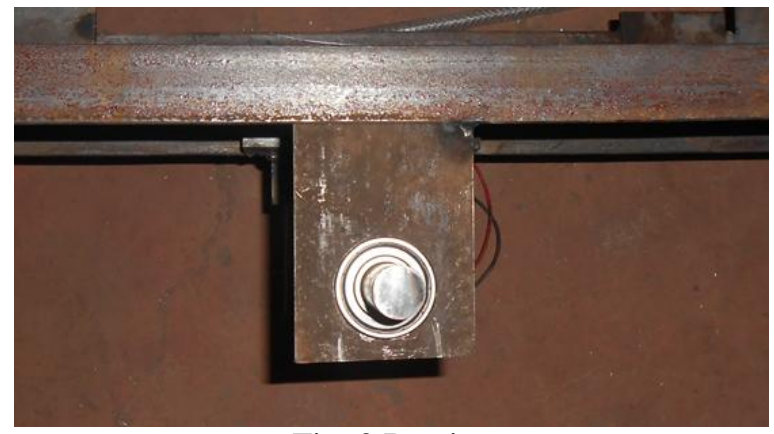

Fig. 3 Bearing

\subsection{Motor and gearbox}

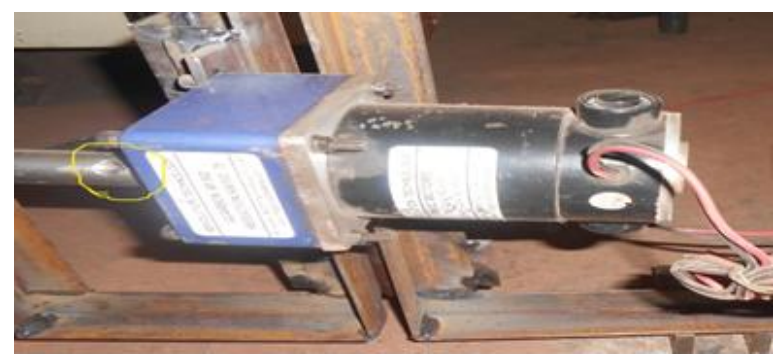

Fig.4 Motor shaft coupled with wheel shaft

The motors used here are DC motors. These are mounted below the structure of the frame. Reduction ratio is 1:50. The motor is of $12 \mathrm{~V} \mathrm{DC}, 4.2 \mathrm{amp}, 1440 \mathrm{rpm}$.

\subsection{Wheels}

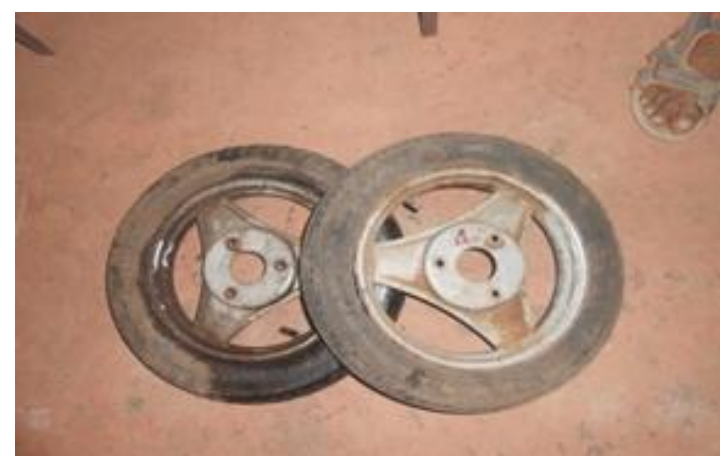

Fig .5 Wheels

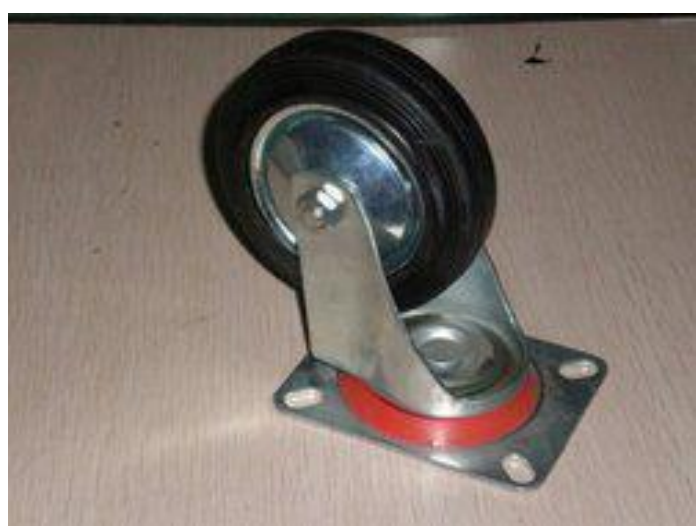

Fig.6 Balancing wheels 


\section{UGC Approved Journal}

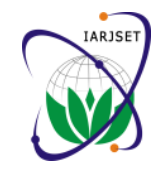

Drive wheel diameter $=34 \mathrm{~cm}$

Balancing wheel diameter $=11.5 \mathrm{~cm}$

\subsection{Handlebar}

Handle bar is the vertical hollow rectangular duct shaped pipe. This is connected at the front side of the chassis in vertically upward direction. It acts as a support for the rider also .A robotic switch is mounted on the wooden block has two buttons which are used for operating Segway as shown in figure.

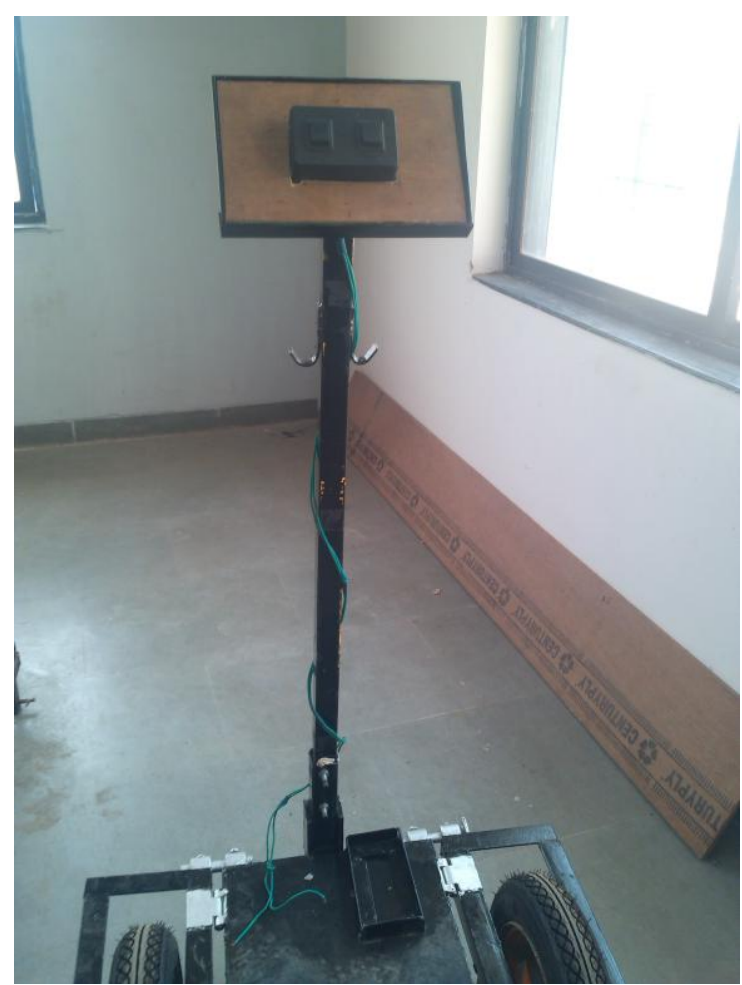

Fig.7Handlebar

\subsection{Electrical connections}

We are using two switches operating two different motors independently. Connection of wires is done accordingly.

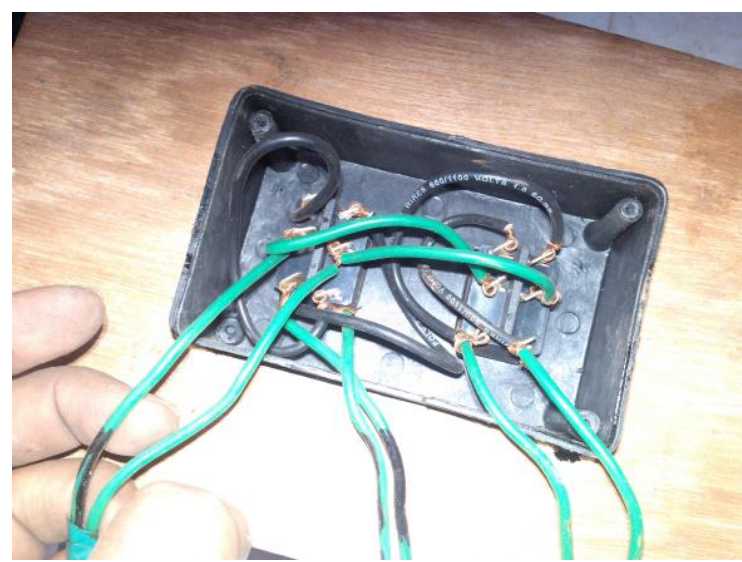

Fig.8 Connections in robotic switch

5 FINAL SPECIFICATIONS

- Top speed $3.6 \mathrm{kmph}$

- Grad ability $5^{0}$

- Four wheel balance

- Runs about 1 hour 
UGC Approved Journal

- 1:50 reduction gearbox

- System weight $=29.5 \mathrm{Kg}$

- Maximum operator weight $=130 \mathrm{Kg}$

- Stopping distance $=0.8 \mathrm{~m}$ ( Experimentally)

- Wheel diameter $=34 \mathrm{~cm}$

- Battery $12 \mathrm{~V} 7.2 \mathrm{~A}$

6 COST COMPARISON

\begin{tabular}{|l|l|l|l|}
\hline Sr no. & Part & Actual segway & Our Segway \\
\hline 1 & Gyroscope & $15000 * 5$ & NA \\
\hline 2 & Micro controller & 60000 & NA \\
\hline 3 & Accelerometer & 6000 & NA \\
\hline 4 & Wheels & $10000 * 2$ & $2000 * 2$ \\
\hline 5 & Li Battery & $77000 * 2$ & 950 \\
\hline 6 & Handle Bar & 12000 & 500 \\
\hline 7 & Lower Cargo Frame & 14200 & 1500 \\
\hline 8 & LED Tail Light & 1000 & NA \\
\hline 9 & Comfort Mat & 9000 & NA \\
\hline 10 & High Speed Motor & $30000 * 2$ & $6000 * 2$ \\
\hline 11 & Gearbox & NA & 2000 \\
\hline 12 & Miscellaneous & NA & 2000 \\
\hline & Total cost & 411200 & 22900 \\
\hline
\end{tabular}

\section{RESULT AND CONCLUSION}

[1] It is found that design is safe for operation with $100 \mathrm{~kg}$ person weight.

[2] We have calculated all the design parameters of design which are useful for segway production and can be used as a benchmark for any other segway production.

[3] Cost of the segway has been brought down upto Rs.22000 from around 3 lakhs.

[4] Gyroscopic unit has been eliminated yet the functionality hasn't been affected.

\section{REFERENCES}

[1] http://www.bbc.com/news/uk-england-14598980

[2] Drive Wheel Motor Torque Calculations, EML2322L - MAE Design and Manufacturing Laboratory.

[3] Manish S. Lade Shubhank C. Jaunjal V. D. Dhopte, "Design and Development of Segway Human Transporter.” IJSRD - International Journal for Scientific Research and Development - Vol. 3, Issue - ISSN (online): 2321-0613, 01, 2015.

[4] M.Thompson, J.Beula Julietta Mary, “ Design and fabrication of failsafe segway personal transporter.”, International Journal of Mechanical and Industrial Technology ISSN 2348-7593 (Online) Vol. 2, Issue 1, pp: (78-82), Month: April 2014 -September 2014.

[6] Ansys Workbench Results.

[7] B. Harshavardhan Reddy, G. Ravi teja Reddy et al "Design and Fabrication of Fail Safe Segway," Presented at the IOSR Journal of Mechanical and Civil Engineering (IOSR-JMCE) e-ISSN: 2278-1684,p-ISSN: 2320-334X, Volume 12, Issue 3 Ver. II ,PP 50-53,(May. - Jun. 2015).

[8] Design of Machine Elements by Prof. V.B.Bhandari.

[9] Reinventing the wheel, TIME magazine December 2001 